\title{
Relatie tussen de beschikbaarheid van een auto van de zaak en lichaamsbeweging
}

\author{
Maarten Koornneef, ${ }^{1}$ Ingrid Hendriksen, ${ }^{2}$ Claire Bernaards ${ }^{2}$
}

\begin{abstract}
Actief transport (zoals lopen of fietsen) kan een belangrijke bijdrage leveren aan de dagelijkse lichaamsbeweging. De beschikbaarheid van een auto van de zaak maakt de keuze voor de auto makkelijker. De gegevens voor deze studie zijn afkomstig uit de enquête Ongevallen en Bewegen in Nederland. Van juli tot september 2011 hebben 1404 personen via internet de voor dit onderzoek relevante vragen omtrent autobezit, de beschikbaarheid van een auto van de zaak en toestemming voor privégebruik volledig beantwoord. Hoofdgebruikers van een auto van de zaak halen minder vaak de combinorm (37\%) dan hoofdgebruikers van een privéauto (54\%), niet-hoofdgebruikers van een auto van de zaak $(52 \%$, niet significant), niet-hoofdgebruikers van een privéauto (54\%), hoofdgebruikers van een privéauto met tevens een auto van de zaak in het huishouden (56\%) en respondenten zonder auto (52\%). Geconcludeerd wordt dat hoofdgebruikers van een auto van de zaak een risicogroep vormen voor bewegingsarmoede. Aanbevolen wordt werknemers en werkgevers te attenderen op dit risico, adviezen te geven over voldoende lichaamsbeweging - waaronder actieve vervoersmogelijkheden en bedrijfsvervoerplannen te ontwikkelen en toe te passen die actief transport stimuleren.
\end{abstract}

Trefwoorden: lichaamsbeweging, combinorm, Nederlandse Norm Gezond Bewegen, fitnorm, leaseauto

\section{INLEIDING}

Voldoende lichaamsbeweging is belangrijk voor de gezondheid door de preventieve en therapeutische werking bij tal van ziekten. ${ }^{1,2}$ Uit diverse bronnen is gebleken dat de hoeveelheid dagelijkse lichaamsbeweging bij een groot deel van de Nederlandse populatie onder het geadviseerde minimumniveau ligt. ${ }^{3,4}$ Er zijn sterke aanwijzingen dat actief transport, zoals lopen of fietsen, een belangrijke bijdrage kan leveren aan de dagelijkse hoeveelheid lichaamsbeweging en daarmee aan de gezondheid. ${ }^{5-14}$ Momenteel omvat actief transport (utilitair en recreatief tezamen) ongeveer $21 \%$ van de wekelijkse tijd die door de Nederlandse volwassen bevolking aan lichaamsbeweging wordt besteed. ${ }^{15}$ In Nederland zijn $70 \%$ van de verplaatsingen korter dan 7,5 kilometer enkele reis. Ongeveer 35\% wordt met de auto gedaan en een vergelijkbaar percentage per fiets. ${ }^{16}$ Voor de Nederlandse situatie wordt geschat dat het vervangen van dagelijkse korte autoritten door verplaatsing per fiets een gemiddelde levensverlenging van drie tot vier maanden oplevert door de extra lichaamsbeweging, ondanks verhoogde inname van luchtverontreiniging (gemiddeld verlies 0,8 tot 40 dagen) en verhoogde kans op sterfte wegens een verkeersongeval (gemiddeld verlies van vijf tot negen dagen)..$^{17}$

Uit verplaatsingsonderzoek is bekend dat autobezit geassocieerd is met meer autogebruik. ${ }^{18}$ Tevens is bekend dat financiële prikkels kunnen leiden tot verandering van verplaatsingsgedrag ${ }^{19}$ en dat het beschikbaar stellen van een auto van de zaak de keuze van een andere vervoerswijze voor het woon-werkverkeer kan ontmoedigen. ${ }^{20-22}$ Onder 'auto van de zaak' valt zowel een personenauto die door of vanwege de werkgever beschikbaar wordt gesteld als een bedrijfspersonenauto die door de eigenaar van het bedrijf zelf wordt gebruikt. In beide gevallen zijn de kosten voor het bedrijf en geldt bij toestemming tot privégebruik een bijtelling bij het persoonlijk inkomen, waarover belasting moet worden betaald. Er is tot dusverre geen onderzoek gedaan naar de relatie tussen de beschikbaarheid van een auto van de zaak in het huishouden en de hoeveelheid lichaamsbeweging. Dit onderzoek heeft tot doel na te gaan of hoofdgebruikers (noot a) van een auto van de zaak en eventuele andere volwassen personen in het huishouden (niet-hoofdgebruikers van een auto van de zaak) risicogroepen vormen voor bewegingsarmoede (noot b) en - indien nodig - aangrijpingspunten te identificeren voor beleidsactie.

\footnotetext{
${ }^{1}$ Ministerie van Volksgezondheid, Welzijn en Sport, Den Haag

2 TNO, Leiden
} 
De volgende onderzoeksvragen zullen worden beantwoord:

- In hoeverre voldoen hoofdgebruikers van een auto van de zaak minder vaak aan de combinorm, (noot c) dan overige naar aanwezigheid en gebruik van een auto te onderscheiden groepen?

- In hoeverre voldoen niethoofdgebruikers van een auto van de zaak minder vaak aan de combinorm dan overige naar aanwezigheid en gebruik van een auto te onderscheiden groepen?

- In hoeverre voldoen personen zonder auto in het huishouden vaker aan de combinorm dan overige naar beschikbaarheid en gebruik van een auto te onderscheiden groepen?

- Voldoen hoofdgebruikers van een auto van de zaak met toestemming voor privégebruik minder vaak aan de combinorm dan hoofdgebruikers van een auto van de zaak zonder toestemming voor privégebruik?

\section{METHODEN}

\section{Dataverzameling}

Voor het beantwoorden van de vraagstellingen is gebruik gemaakt van de TNO monitor Bewegen en Gezondheid, onderdeel van Ongevallen en Bewegen in Nederland (OBiN). OBiN is een continu uitgevoerde enquête onder de Nederlandse bevolking. Per kwartaal worden netto ruim 2500 deelnemers bevraagd via een steekproef uit een panel van ongeveer 238.000 personen dat representatief is voor de Nederlandse bevolking. De dataverzameling binnen de groep 15 tot 64 jarigen vindt voor ruim $85 \%$ plaats via een online webenquête en voor het overige deel via telefonische computerondersteunde bevraging (noot d). De peilingperiode was van 1 juli 2011 tot en met 30 september 2011. Voor dit onderzoek zijn alleen de data gebruikt van volwassen deelnemers (18-64 jaar) die de online webenquête hebben ingevuld.

\section{Vragenlijst}

In de monitor wordt gevraagd naar het aantal dagen van een gemiddelde week dat men minimaal 30 minuten minstens matig intensief beweegt. Indien zowel in de zomer als in de winter doorgaans op minstens vijf dagen per week deze mate van lichaamsbeweging wordt gehaald, voldoet men aan de Nederlandse Norm Gezond Bewegen (NNGB). Ook wordt het aantal maal per week dat men 20 minuten intensief beweegt nagevraagd. Indien de respondent aangeeft zowel in de zomer als in de winter doorgaans minstens drie maal per week ten minste 20 minuten intensief te bewegen, voldoet hij of zij aan de fitnorm. Indien men de NNGB en/of de fitnorm haalt, voldoet men aan de combinorm. De vragenlijst is in eerder onderzoek gevalideerd. ${ }^{23}$ In recent gepubliceerd onderzoek is de vragenlijst vergeleken met een objectief instrument. ${ }^{24}$

In de peilingperiode zijn ten behoeve van dit onderzoek enkele extra vragen over het aantal auto's in het huishouden en de beschikbaarheid van een auto van de zaak (bijvoorbeeld een leaseauto) aan OBiN toegevoegd. Bij beschikbaarheid van een auto van de zaak in het huishouden is gevraagd naar toestemming voor privégebruik.

In OBiN wordt standaard gevraagd naar geslacht en leeftijd, de hoogst genoten opleiding (noot e), het hebben van een chronische aandoening (noot $\mathrm{f})$, het hebben van betaald werk en het land van herkomst (noot g).

\section{Statistische analyse}

In dit onderzoek zijn alleen de gegevens binnen de doelgroep 18-64 jaar geanalyseerd van degenen die per internet zijn geënquêteerd $(\mathrm{N}=1714)$, omdat in eerdere peilingperioden van OBiN een aanzienlijk verschil is gebleken in het halen van de combinorm met respondenten die per telefoon werden bevraagd, hetgeen bij combinatie van beide enquêtemethoden artefacten zou kunnen veroorzaken. ${ }^{25}$ Voor het beantwoorden van vraagstellingen worden de volgende zes niet-overlappende gebruikersgroepen onderscheiden:

1 hoofdgebruikers van een auto van de zaak;

2 hoofdgebruikers van een privéauto;

3 niet-hoofdgebruikers van een auto van de zaak;

4 niet-hoofdgebruikers van een privéauto;

5 niet-hoofdgebruikers van een auto van de zaak, maar wel hoofdgebruikers van een privéauto;

6 respondenten zonder auto in het huishouden.

Het formeren van de groep 'niet-hoofdgebruikers van een auto van de zaak, tevens hoofdgebruiker van een privéauto' werd noodzakelijk geacht omdat het niet verantwoord werd gevonden deze respondenten toe te wijzen aan de groep 'hoofdgebruikers van een privéauto' dan wel aan de groep 'niet-hoofdgebruikers van een auto van de zaak'. De verschillen in achtergrondkenmerken (leeftijd, geslacht, chronische aandoening(en), opleidingsniveau, land van herkomst en het hebben van betaald werk) tussen de groepen werden tweezijdig getoetst met de chikwadraattoets (voor de categorische variabelen) en Kruskal-Wallis test (voor de continue variabele leeftijd). Er werd tweezijdig getoetst met een $\alpha$ van 0,05 . Ter beantwoording van onderzoeksvragen 1, 2 en 3 zijn, na codering van de zes gebruikersgroepen in dummyvaria- 
belen, aparte multipele lineaire regressieanalyses uitgevoerd met de combinorm en met de onderliggende NNGB en fitnorm als afhankelijke variabelen. Om de verschillen tussen de groepen op significantie te toetsen, werd de groep 'hoofdgebruikers van een auto van de zaak' als referentiegroep genomen voor het beantwoorden van onderzoeksvraag 1, de groep 'niet hoofdgebruikers van een auto van de zaak' voor het beantwoorden van onderzoeksvraag 2 en de groep respondenten zonder auto in het huishouden voor het beantwoorden van onderzoeksvraag 3. Per afhankelijke variabele (combinorm, NNGB en fitnorm) zijn eerst alleen de variabelen voor de groepen opgenomen in het regressiemodel ter bepaling van de groepsverschillen. Daarna zijn de achtergrondkenmerken (i.e. leeftijd, land van herkomst, het hebben van een chronische aandoening en het hebben van betaald werk) opgenomen in het regressiemodel om te onderzoeken of en in hoeverre de groepsverschillen blijven bestaan na correctie voor deze potentiële confounders. Indien de verschillen na correctie nog steeds significant of relevant zijn biedt dat steun aan de gemaakte aannames over de relatie van een auto van de zaak, dan wel het hoofdgebruikerschap met beweeggedrag. Er is voor lineaire regressie gekozen omdat op deze manier absolute verschillen kunnen worden gepresenteerd voor elk van de groepen waardoor voor de (beleids)praktijk een goed inzicht kan worden verkregen in de maatschappelijke relevantie van de onderzoeksresultaten. ${ }^{26}$ Onderzoeksvraag 4 is onderzocht door toetsing van het verschil tussen de groep met toestemming tot privégebruik van de auto van de zaak en zonder toestemming tot privégebruik met de chikwadraattoets. De analyses zijn verricht op de data van de respondenten die op alle onderzochte variabelen valide antwoorden gaven. Een verschil van 5 procentpunten in het percentage normactieven (noot $\mathrm{h}$ ) werd als relevant beschouwd gezien de inzet van de overheid voor een opwaarts verschil in die orde van grootte. ${ }^{27,28}$ Er werd gebruik gemaakt van SPSS 20.

\section{RESULTATEN}

In de peilingperiode werden 1714 personen binnen de leeftijdscategorie van 18-64 jaar per internet bevraagd, waarvan 1404 (82\%) de vragen ter bepaling van combinorm, NNGB en fitnorm, de vragen over de beschikbaarheid en het gebruik van auto's in hun huishouden en de vragen naar relevante achtergrondkenmerken volledig beantwoordden.

Er zijn significante verschillen tussen de gebruikersgroepen voor alle achtergrondkenmerken, behalve voor herkomst (tabel 1). De hoofdgebruikers van een auto van de zaak zijn vaker man en geven minder vaak aan gezondheidsklachten te hebben.

Tabel 2 geeft een overzicht van de verschillen tussen hoofdgebruikers van een auto van de zaak en de overige groepen in het halen van de respectievelijk de combinorm, de NNGB en de fitnorm voor en na correctie voor de mogelijke invloed van achtergrondkenmerken op het halen van de normen. Het percentage hoofdgebruikers van een auto van de zaak dat de combinorm haalt, is relevant lager dan dat van andere groepen. De verschillen zijn significant, behalve het verschil met niet-hoofdgebruikers van een auto van de zaak.

Niet-hoofdgebruikers van een auto van de zaak verschillen niet significant van andere groepen; alleen het verschil met hoofdgebruikers van een auto van de zaak is relevant. De groep personen zonder auto in het huishouden haalt alleen significant en relevant vaker de combinorm dan hoofdgebruikers van een auto van de zaak, maar haalt niet vaker de combinorm dan de overige groepen.

Uit tabel 2 blijkt tevens dat het lage percentage in het halen van de combinorm binnen de groep hoofdgebruikers van een auto van de zaak vooral gebaseerd is op het significant en relevant minder vaak voldoen aan de NNGB. De verschillen met andere groepen in het halen van de fitnorm zijn niet significant en na correctie slechts relevant ten opzichte van niet-hoofdgebruikers van een privéauto.

Verder blijkt uit tabel 2 dat de groep niet-hoofdgebruikers van een privéauto met tevens een auto van de zaak in het huishouden het vaakst voldoet aan de combinorm, NNGB en fitnorm. Het verschil met andere groepen is vrijwel steeds relevant, maar slechts het verschil met hoofdgebruikers van een auto van de zaak in het voldoen aan combinorm en NNGB is ook significant.

Uit de analyse naar het effect van selectie door het uitsluiten van online respondenten die niet alle vragen beantwoordden (niet in tabel) blijkt geen vertekening van de gevonden associaties. De analyse met toevoegen van de groep telefonische respondenten $(\mathrm{n}=221$, niet in tabel) geeft geen ander beeld. Uit de aanvullende analyse van alleen de groep telefonische respondenten blijkt dat de verschillen naar type autobezit niet significant zijn. Analyse met enkele andere variabelen die beperkte associaties met de combinorm vertoonden (stedelijkheid van de woonomgeving, hoogste opleiding van de kostwinner, huishoudgrootte en aantal auto's in het huishouden, niet in tabel) leverde geen ander beeld op.

Binnen de groep hoofdgebruikers van een auto van de zaak heeft $83 \%$ toestemming voor privé-gebruik (niet in tabel). Degenen met toestemming tot privégebruik $(\mathrm{n}=112)$ lijken minder vaak te voldoen aan de combinorm (37\% versus 39\%), NNGB (25\% versus 30\%) en fitnorm (17\% versus $22 \%$ ) dan degenen die geen toestemming hebben voor privégebruik. Deze verschillen zijn niet significant.

\section{DISCUSSIE}

Dit is het eerste gerapporteerde onderzoek naar de relatie tussen het kunnen beschikken over een auto van de zaak en het beweeggedrag van de hoofdgebruiker en de eventuele andere volwassen personen in het huishouden. Uit dit onderzoek blijkt, conform verwachting, dat hoofdgebruikers van een auto van de zaak relevant minder vaak voldoen aan de combinorm dan de overige groepen van respondenten, hoewel het verschil met de groep niet-hoofdgebruikers van een auto van de zaak niet significant is. Toestemming voor privégebruik van de auto van de zaak lijkt de negatieve relatie met het halen van de combinorm, NNGB en fitnorm te versterken, maar de associaties zijn niet significant. 

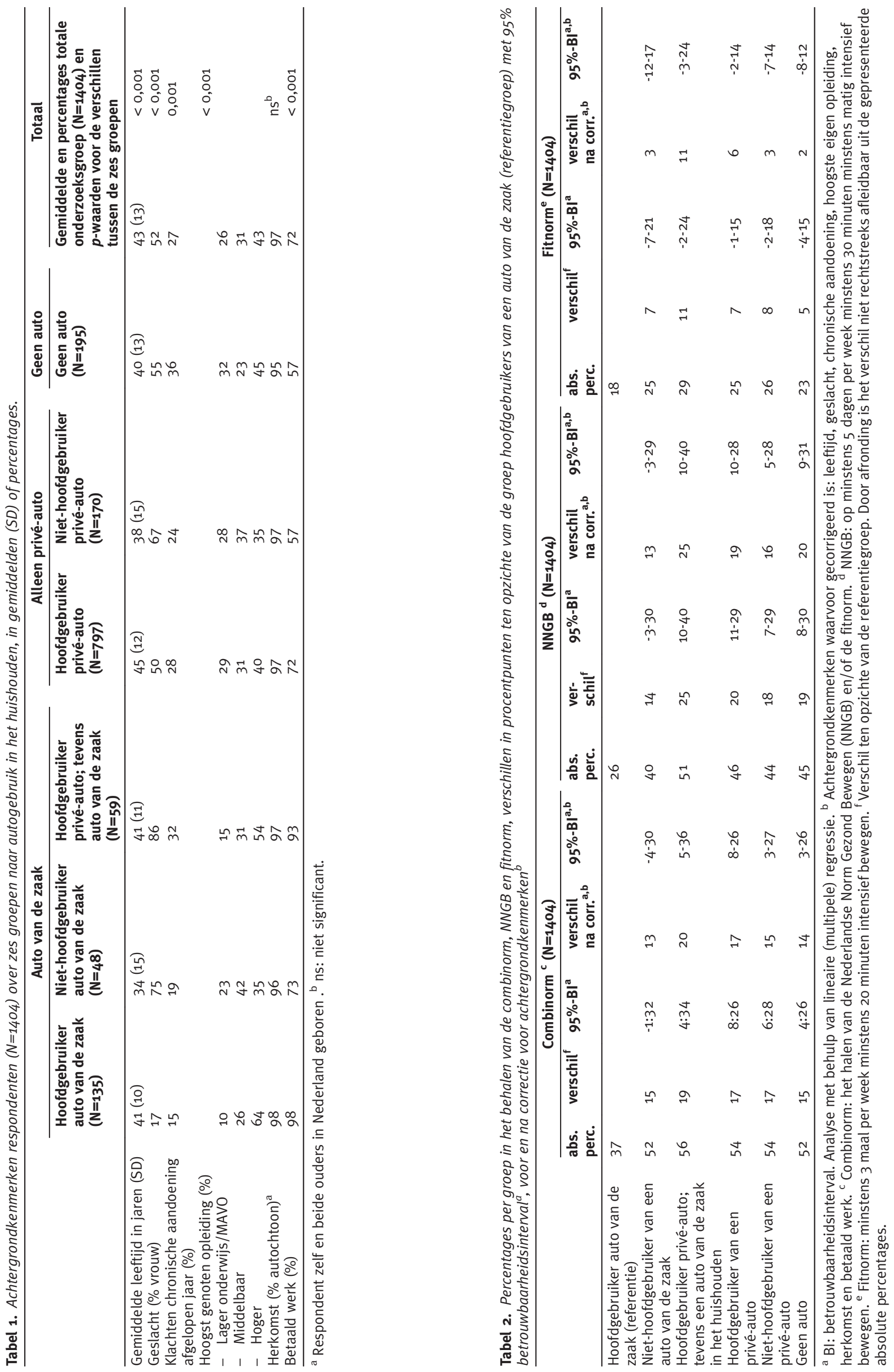
Een belangrijke bevinding in dit onderzoek is dat de beschikbaarheid van een auto van de zaak niet geassocieerd is met bewegingsarmoede bij de overige volwassen personen in het huishouden. De groep niet-hoofdgebruikers van een auto van de zaak verschilt niet van groepen met een privéauto in het huishouden of de groep zonder auto in het huishouden. Hoofdgebruikers van een privéauto met tevens nog een auto van de zaak in het huishouden halen zelfs het vaakst de combinorm, NNGB en fitnorm. De verschillen zijn weliswaar alleen significant vergeleken met hoofdgebruikers van een auto van de zaak, maar vrijwel steeds relevant. Een mogelijke verklaring kan zijn dat het gaat om hoog opgeleide vrouwen. Zij zijn mogelijk meer gezondheidsbewust en/of hebben meer tijd en geld om aan sport en/of fitness deel te nemen.

Tegen de verwachting in halen mensen zonder auto in het huishouden niet vaker de combinorm dan mensen met een privéauto in het huishouden. Zij vormen overigens wel een bijzondere groep: zij hebben vaker een laag opleidingsniveau, geven vaker aan gezondheidsklachten te hebben en wonen vaker in zeer stedelijke gebieden (niet in tabel).

De bevinding dat hoofdgebruikers van een auto van de zaak minder vaak de combinorm halen, kan meerdere oorzaken hebben. Zo zullen zij vermoedelijk meer tijd doorbrengen in de auto. De aard van het werk kan een verklaring zijn evenals het aantal gewerkte uren, waardoor zij mogelijk minder tijd hebben om te sporten. Uit ander onderzoek is bekend dat bewegingsarmoede op het werk niet automatisch gecompenseerd wordt met meer bewegen in de vrije tijd. ${ }^{29}$ De bevinding in dit onderzoek dat hoofdgebruikers van een auto van de zaak ook het minst vaak voldoen aan de fitnorm, past daarbij. Er zijn evenwel onvoldoende gegevens om nadere uitspraken te doen over bewegen op het werk en in de vrije tijd.

Voorzichtigheid bij het interpreteren van de resultaten is geboden. Omdat het gaat om een dwarsdoorsnede-onderzoek kunnen geen conclusies worden getrokken over de causaliteit van de gevonden relaties. Ook was er onvoldoende informatie voorhanden over andere mogelijk relevante achtergrondkenmerken, zoals sportdeelname en kenmerken van beroep en/of branche waarin de respondenten werkzaam zijn.

Het gegeven dat dit onderzoek gebaseerd is op zelf gerapporteerd gedrag noopt tot voorzichtigheid bij het interpreteren van de cijfers. Er is echter geen aanleiding te veronderstellen dat hoofdgebruikers van een auto van de zaak de vragen systematisch anders hebben beantwoord dan de overige groepen. De gevonden groepsverschillen binnen de online respondenten stemmen niet volledig overeen met de resultaten binnen de telefonische respondenten. Maar ook binnen die subgroep is er een tendens dat hoofdgebruikers van een auto van de zaak een verhoogd risico lopen op bewegingsarmoede.

Voordat kan worden overgegaan tot (fiscale) maatregelen om het gebruik van de auto van de zaak te ontmoedigen, zal nader onderzocht moeten worden of deze gebruikers een specifieke groep vormen met betrekking tot onder andere type werk en aantal werkuren per week. Ook zal onderzocht moeten worden welke dagelijkse lichamelijke activiteiten het meest te lijden hebben onder het gebruik van een auto van de zaak, bijvoorbeeld door onderzoek uit te voeren bij mensen die voor het eerst de beschikking krijgen over een auto van de zaak. Tevens is onderzoek nodig onder hoofdgebruikers van een auto van de zaak om na te gaan of veranderingen in de voorwaarden waaronder de auto van de zaak mag worden gebruikt en/of het niet langer kunnen beschikken over een auto van de zaak van invloed is op de hoeveelheid lichaamsbeweging. Wel kan op basis van dit onderzoek worden geconcludeerd dat er sterke aanwijzingen zijn dat hoofdgebruikers van een auto van de zaak een verhoogd risico lopen op bewegingsarmoede. Dit is een belangrijke bevinding, want het gaat landelijk om een aanzienlijk aantal mensen. Volgens de Vereniging van Nederlandse Autoleasemaatschappijen was eind 2011 het aantal geleaste personenauto's gestegen tot $466.100 .^{30}$ Uit gegevens van het ministerie van Financiën is gebleken dat er in 2010 ongeveer 720.000 auto's van de zaak fiscaal belast beschikbaar waren voor privégebruik. ${ }^{31}$ De Vereniging Auto Van De Zaak komt eind 2011 tot ongeveer 1 miljoen zakelijke rijders. ${ }^{32}$

\section{AAN BEVELINGEN}

Op basis van dit onderzoek wordt aanbevolen om werkgevers en werknemers te attenderen op het risico van bewegingsarmoede onder werknemers die beschikken over een auto van de zaak, en om hoofdgebruikers van een auto van de zaak adviezen te geven over regelmatige lichaamsbeweging en hen te wijzen op de mogelijkheden van actief transport. Voor onderbouwde interventies voor sport en bewegen zijn actuele overzichten beschikbaar, hoewel niet specifiek voor hoofdgebruikers van een auto van de zaak. ${ }^{33,34}$ Werkgevers kunnen vervoerplannen invoeren die actief transport stimuleren. ${ }^{35}$ Er zijn al bedrijven die bijvoorbeeld hun medewerkers extra betalen voor gefietste zakelijke kilometers of een OV-kaart verstrekken in plaats van, of in aanvulling op, een auto van de zaak. ${ }^{36}$ Autoleasemaatschappijen zouden hun aanbod kunnen uitbreiden met dienstverleningsproducten waarin transport per fiets en openbaar vervoer zijn opgenomen.

\section{DAN KWOORD}

Dit onderzoek is verricht in het kader van de Medische Vervolg Opleiding Arts Maatschappij \& Gezondheid tweede fase van de Netherlands School of Public and Occupational Health (NSPOH) van de eerste auteur. Wij willen Gaby Vullings van Ipsos Synovate en Astrid Chorus van TNO bedanken voor hun adviezen over de bestanden en extra vragen, Francisca Galindo Garre, Elise Dusseldorp en Hedwig Hofstetter van TNO voor hun statistische adviezen en de leergroep van de NSPOH onder leiding van Willy-Anne van Stiphout voor het kritisch meedenken bij de opzet, uitvoering en verslaglegging van het onderzoek. 


\section{NOTEN}

a Onder 'hoofdgebruiker' wordt verstaan: degene binnen het huishouden die de meeste kilometers met een auto rijdt.

b Onder 'bewegingsarmoede' wordt verstaan het nietvoldoen aan de 'combinorm'.

c Onder 'combinorm' wordt verstaan: het voldoen aan de Nederlandse Norm Gezond Bewegen (NNGB) en/ of de 'fitnorm':

- Nederlandse Norm Gezond Bewegen (NNGB) voor volwassenen: op ten minste 5 dagen per week minstens 30 minuten minstens matig intensief bewegen; - fitnorm: minstens 3 maal per week minstens 20 minuten intensief bewegen.

d OBiN peilt via vrijwel dagelijkse enquêtes per telefoon en via internet onder meer naar ongevalletsel en lichaamsbeweging. OBiN wordt uitgevoerd sinds 2000 in opdracht van het ministerie van Volksgezondheid, Welzijn en Sport. Voor een uitgebreide beschrijving van OBiN en de vragenlijst zie: http://www.veiligheid.nl/ onderzoek/ongevallen-en-bewegen-in-nederland

e Antwoordcategorieën: 1. WO, 2. HBO, 3. HAVO/ VWO, 4. MBO, 5. LBO/VMBO/MAVO, 6. Basisonderwijs/geen onderwijs), 7. Geen antwoord.

f Vraagtekst chronische aandoening: Heeft $\mathrm{u}$ in de afgelopen 12 maanden last gehad van een of meer langdurige ziekten of aandoeningen?

g Vraagtekst herkomst (drie vragen): In welke land bent $\mathrm{u}$ (is uw vader/moeder) geboren: 1. Nederland, 2 . Turkije, 3.Marokko, 4. Suriname, 7. België, 8. Duitsland, 9. Indonesië (Nederlands-Indië), 5. anders, 6. geen antwoord.

h Onder 'normactief' wordt verstaan het voldoen aan de combinorm, NNGB of fitnorm.

\section{ABSTRACT}

Relationship between the availability of a business car and physical activity

Active transport may contribute substantially to daily physical activity. However, availability of a business car facilitates the choice for the car as mode of transport. For this study data of the permanent survey Injuries and Physical Activity in the Netherlands were used. From July to September 2011, 1404 online respondents answered to all relevant questions about car ownership, the availability of a business car and permission for private use. Main users of a business car comply less to the physical activity guidelines $(37 \%)$ than main users of a private car $(54 \%)$, non-main users of a business car (52\%, not significant), non-main users of a private car (54\%), main users of a private car with also a business car in the household (56\%) and respondents without a car (52\%). Conclusion: main users of a business car are at risk for insufficient physical activity. Recommendations are to point out this risk to employers and employees, to advice them about ways to increase their physical activity including active transport options, and to develop and implement company transport arrangements that stimulate active transport.

Keywords: physical activity, physical activity standard, lease car, business car

\section{LITERATUUR}

1. Physical activity and health: a report of the Surgeon General. Atlanta, GA, USA: U.S. Department of Health and Human Services, Centers for Disease Control and Prevention, National Center for Chronic Disease Prevention and Health Promotion, 1996.

2. Lee I-M, Shiroma EJ, Lobel F, Puska P, Blair SN, Katzmarzyk PT. Effect of physical inactivity on major non-communicable diseases worldwide: an analysis of burden of disease and life expectancy. Lancet 2012;380:219-29.

3. Hildebrandt VH, Chorus AMJ, Stubbe JH. Trendrapport Bewegen en Gezondheid 2008/2009. Leiden: TNO Kwaliteit van Leven, 2010.

4. Wendel-Vos GCW. Hoeveel mensen zijn voldoende lichamelijk actief? In: Volksgezondheid Toekomst Verkenning, Nationaal Kompas Volksgezondheid. Van: www.nationaalkompas.nl/ gezondheidsdeterminanten/leefstijl/lichamelijke-activiteit.

5. Andersen LB, Schnohr P, Schroll M, Hein HO. All-cause mortality associated with physical activity during leisure time, work, sports and cycling to work. Arch Int Med 2000;160:1621-8.

6. Cavill N, Kahlmeier S, Rutter H.Racioppi F, Oja P. Economic analyses of transport infrastructure and policies including health effects related to cycling and walking: a systematic review. Transport Policy 2008;15:291-304.

7. Kahlmeier S, Racioppi F, Cavill N, Rutter H, Oja P."Health in All Policies" in Practice: Guidance and Tools to Quantifying the Health Effects of Cycling and Walking. J Phys Activity Health 2010;7(Suppl 1):S120-5.

8. Hendriksen IJM. The effect of commuter cycling on physical performance and on coronary heart disease risk factors. Thesis. Amsterdam: Vrije Universiteit, 1996.

9. Geus B de. Cycling to work: psychosocial and environmental factors associated with cycling and the effect of cycling on fitness and health indexes in an untrained working population. Thesis. Brussel: Vrije Universiteit Brussel (VUB), 2007.

10. Larouche R, Saunders TJ, Faulkner GEJ, Colley R, Tremblay M. Associations Between Active School Transport and Physical Activity, Body Composition and Cardiovascular Fitness: A Systematic Review of 68 Studies. J Phys Activity Health 2012 Dec 17 [Epub ahead print].

11. Saunders LE, Green JM, Petticrew MP, Steinbach R, Roberts $H$. What Are the Health Benefits of Active Travel? A Systematic Review of Trials and Cohort Studies. Plos one, 2013;8(8): e69912. doi:10.1371/journal.pone.0069912.

12. Yang L, Sahlqvist S, McMinn A, Griffin SJ, Ogilvie D. Interventions to promote cycling: systematic review. BMJ 2010;341: c5293.

13. Cooper AR, Wedderkopp N, Jago R, Kristensen PL, Moller NC, Froberg $K$, et al. Longitudinal associations of cycling to school with adolescent fitness. Prev Med 2008;47:324-8.

14. Geus B de, Joncheere J, Meeusen R. Commuter cycling: effect on physical performance in untrained men and women in Flanders: minimum dose to improve indexes of fitness. Scand J Med Sci Sports 2009;19:179-87.

15. Bewegen in Nederland 2000-2010. Resultaten TNO-monitor Bewegen en Gezondheid. Leiden: TNO, 2011. http:// www.vng.nl/Documenten/actueel/beleidsvelden/cultuur_sport/2011/20110712_factsheet_bewegen_2000_2010.pdf

16. Ministerie van Infrastructuur en Milieu. Mobiliteitsbalans 
2012. Kennisinstituut voor Mobiliteitsbeleid Den Haag: Ministerie van Infrastructuur en Milieu, 2012.

17. Hartog JJ de, Boogaard H, Nijland H, Hoek G. Do the health benefits of cycling outweigh the risks? Environ Health Perspect2010;118:1109-16.

18. Ministerie van Verkeer en Waterstaat, Rijkswaterstaat. Mobiliteit in cijfers 2004. Resultaten uit het eerste jaar Mobiliteitsonderzoek Nederland. Den Haag: Ministerie van Verkeer en Waterstaat, Rijkswaterstaat, Adviesdienst Verkeer en Vervoer, 2005, blz 36.

19. Cervero R, Creedman N, PohanM, Pai M, Tsai Y-H. City CarShare. Assessment of intermediate-term travel-behavior impacts. Berkeley: Institute of Urban and Regional Development, University of California at Berkeley, 2002.

20. Dickinson JE, Kingham S, Copsey S, Pearlman Hougie DJ. Employer travel plans, cycling and gender: will travel plan measures improve the outlook for cycling to work in the UK? Transportation Res Part D 2003;8(1):53-67.

21. Kingham S, Dickinson J, Copsey S. Travelling to work: will people move out of their cars? Transport Policy 2001;8(2):15160.

22. Wagt van der J. Verbieden die leaseauto. Intermediair 2 februari 2011, http://www.intermediair.nl/carriere/salaris/arbeidsvoorwaarden/verbieden-die-leaseauto.

23. Hildebrandt VH, Douwes M. Vragen naar de mate van lichamelijke activiteit; validatiestudie Onderzoek naar de test-hertest betrouwbaarheid en congruente validiteit van een vragenlijst. Geneeskunde en Sport 2000;33:9-16.

24. Hollander EL de, Zwart L, De Vries SI, Wendel-Vos W. The SQUASH was a more valid tool than the OBiN for categorizing adults according to the Dutch physical activity and the combined guideline. J Clin Epidem 2012;65:73-81.

25. Chorus AMJ, Galindo Garre F, Stubbe JH, Hoekman R, S Schmikli S. 'Mixed Mode Design' van de Monitor Ongevallen en Bewegen in Nederland (OBiN): Steekproef- en methodeeffect onderzocht. Publicatienummer 2010.069 Opdrachtgever Ministerie van Volksgezondheid, Welzijn en Sport. Leiden: TNO Kwaliteit van Leven, 2010.

26. Stiphout W-A van, Burema J. Cijfers de baas. Het 8-stappenplan als hulpmiddel bij het lezen van wetenschappelijke literatuur voor de praktijk. Tijdschr Gezondheidswet 2006;84:124-5.
27. Wendel-Vos GCW, Ooijendijk WTM, Baal PHM van et al. Kosteneffectiviteit en gezondheidswinst van behalen beleidsdoelen bewegen en overgewicht.Onderbouwing Nationaal Actieplan Sport en Bewegen. Bilthoven: RIVM, 2005, p 85.

28. Ministerie van Volksgezondheid, Welzijn en Sport. Beleidsnota Tijd voor sport - Bewegen, Meedoen, Presteren. Den Haag, Ministerie van VWS, 2005, p 27-28.

29. Hildebrandt VH, Chorus AMJ,Tiessen-Raaphorst A. Volwassenen: sport, bewegen en werk (H7). In: SCP. Sport: een leven lang. Rapportage sport. Den Haag/'s Hertogenbosch: Sociaal en Cultureel Planbureau/W.J.H. Mulier Instituut, 2010, p 12536.

30. Vereniging van Nederlandse Autoleasemaatschappijen. http:// www.vna-lease.nl/VNA/show.do?ctx=1346,1365\&anav=65917, geraadpleegd op 1 februari 2012.

31. Ministerie van Financiën. http://www.rijksoverheid.nl/nieuws/ 2011/05/24/15-miljoen-euro-aan-boetes-en-naheffingenvoor-misbruik-auto-van-de-zaak.html.

32. Vereniging Auto Van De Zaak. http://www.verenigingautovandezaak.nl/nieuws/details/2012_kilometervergoeding_bpm_bijtelling, geraadpleegd op 1 februari 2012.

33. RIVM Centrum Gezond Leven. http://www.loketgezondleven.nl/interventies/kwaliteit-van-interventies/beoordeeldeinterventies/, geraadpleegd op 20 maart 2013.

34. Hendriksen IJM, Fekkes M, Butter M, Hildebrandt VH. Stimuleren van fietsen naar het werk. Beleidsadvies in opdracht van het Ministerie van Volksgezondheid, Welzijn en Sport (VWS). Publicatienummer 2010.033, p 53-57. Leiden: TNO, Kwaliteit van Leven, 2010.

35. Nederlands Instituut voor Sport en Bewegen. http://www.netwerkinbeweging.nl/interventie-home, geraadpleegd op 20 maart 2013.

36. World Café Innovatie in Leasewereld: Mobiliteit. http:// slimwerkenslimreizen.nl/index.html?artikel_ID=3\&lo$\mathrm{cl}=3$ \&art=3\&commart=688\&naam=Kalender, geraadpleegd op 29 maart 2012.

\section{CORRESPONDENTIEADRES}

Maarten Koornneef, Muur 84, 1422 PL Uithoorn, tel.06-54718454, e-mail: maarten.koornneef@planet.nl 